\title{
Mechanisms of the training response in patients with peripheral arterial disease - a review
}

\author{
B Parr (MSc) ${ }^{1}$ \\ Y Albertus-Kajee (PhD) ${ }^{2}$ \\ E W Derman (MB ChB, PhD, FACSM, FFIMS) ${ }^{2}$ \\ ${ }^{1}$ Cape Peninsula University of Technology \\ ${ }^{2}$ UCT/MRC Research Unit for Exercise Science and Sports Medicine, Department of Human Biology, Faculty of Health Sciences, University of \\ Cape Town and Sports Science Institute of South Africa
}

\begin{abstract}
Exercise training has proved to be a beneficial treatment for patients with peripheral arterial disease (PAD) suffering from the symptom of intermittent claudication. The mechanism by which symptomatic improvement occurs is unclear. The review summarises the mechanism of the training response in patients with $\mathrm{PAD}$, focusing on improvements in bloodflow as well as biochemical, muscle recruitment and psychological adaptations. Possible areas of future research are suggested.
\end{abstract}

\section{Introduction}

Peripheral arterial disease (PAD) is characterised by the presence of atherosclerotic plaque in the peripheral arteries causing reduced blood flow to the peripheral limbs. Reduced blood flow results in ischaemia. The pain of intermittent claudication is felt, particularly during exercise. ${ }^{1}$ The word 'claudicare' means to limp. Typically the patient with PAD will experience pain (either in the buttock, thigh or calf muscle) distal to the atherosclerotic obstruction. Studies have shown that exercise training is an important and effective therapy for patients with PAD. The effects of exercise training on PAD and

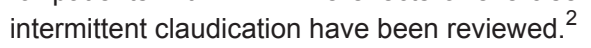

Typically exercise programmes continue for 6 weeks to 6 months and vary in the mode of exercise training used. In a meta-analysis by Gardner et al. ${ }^{18}$ of 21 studies on exercise training in patients with PAD, PFWD increased $179 \%$ and the MWD increased $122 \%$ following exercise training. ${ }^{18}$ Despite the clear evidence of patients

\section{CORRESPONDENCE:}

Yumna Albertus

UCT/MRC Research Unit for Exercise Science and Sports Medicine

Sports Science Institute of South Africa

PO Box 115

Newlands, 7725

Phone: +27 216504567

Fax: $\quad+27216867530$

E-mail: Yumna.Albertus@uct.ac.za clinically benefiting from exercise training, the mechanism(s) of the training response remains unclear. Several mechanisms have been proposed and researched and these will be discussed in this paper.

\section{Improvements in blood flow - increased collateral circulation and increased endothelium-dependent dilation}

Skinner and Strandness ${ }^{3}$ claimed that exercise training increased collateral circulation to the ischaemic muscle. They found a reduction in the post-exercise hyperaemic response with exercise training. ${ }^{3}$ Postexercise hyperaemia is when blood flow increases to the ischaemic muscle after exercise, and as a result blood flow decreases to the foot, causing a reduction in ankle pressure. The greater the reduction in ankle pressure, the greater the extent of the underlying peripheral arterial disease as blood is shunted to the ischaemic muscle. ${ }^{19}$ Therefore the authors argued that because this post-exercise hyperaemic response was dampened by exercise training, exercise training must improve blood flow to the ischaemic limb and stated that this was through collateral growth (although they did not prove this).

In that same period, Alpert et al. ${ }^{4}$ documented that exercise training increased absolute blood flow to the lower limbs (measured by the ${ }^{133} \mathrm{Xe}$ clearance method) and also attributed this to the development of a collateral circulation. ${ }^{4}$

Twenty years later a study by Carter et al. ${ }^{5}$ also found that systolic ankle pressure recovery to normal levels following the post-exercise hyperaemic response was more rapid after a period of exercise training. Furthermore, an increase in walking tolerance was related to a decrease in the time of the ankle pressure to return to pre-exercise levels but not to any other haemodynamic variables (absolute ankle pressure and $\mathrm{ABI}$ ), ${ }^{5}$ and therefore the development of an increased collateral circulation and improved blood flow was unlikely. In support of this study, Jonason and Ringqvist ${ }^{6}$ found that post-exercise ankle pressure (from minute 2 - 16) was higher after a period of exercise training. However, there was no change in calf blood flow at rest or post-ischaemic maximum blood flow measured by strain gauge plethysmography. They attributed this reduction in post-exercise hyperaemia to 'a more optimal distribution and utilization of available blood flow with exercise training. ${ }^{6}$

Therefore neither Carter et al. ${ }^{5}$ or Jonason and Ringqvist ${ }^{6}$ could attribute increased walking tolerance following exercise training to increased blood flow to the lower limb through an increased collateral circulation. Subsequently two more studies have shown that blood flow to the lower limb as measured by strain gauge plethysmography increases with exercise training. ${ }^{7,8}$ However, neither of the above 
TABLE I. Review of the trials determining the mechanism of the training response in patients with PAD

\begin{tabular}{|c|c|c|c|}
\hline Authors & Proposed mechanism of response & Effect of exercise training & Variable measured \\
\hline Skinner and Strandness ${ }^{3}$ & Increase in collateral circulation & $\begin{array}{l}\text { The decrease in AP with exercise } \\
\text { was less after training }\end{array}$ & Ankle pressure \\
\hline Carter et al. ${ }^{5}$ & $\begin{array}{l}\text { Redistribution of blood flow, } \\
\text { increased capacity of skeletal } \\
\text { muscles }\end{array}$ & $\begin{array}{l}\text { Time for post-exercise ankle pres- } \\
\text { sure to reach normal levels after } \\
\text { exercise was less. } \\
\text { No change in } \mathrm{ABI} \text { or } \mathrm{AP}\end{array}$ & $\begin{array}{l}\text { Systolic AP recovery } \\
\text { ABI } \\
\text { AP absolute }\end{array}$ \\
\hline Jonason and Ringqvist ${ }^{6}$ & $\begin{array}{l}\text { More optimal distrib and utilisa- } \\
\text { tion of available blood flow with } \\
\text { exercise training }\end{array}$ & $\begin{array}{l}\text { Post-exercise AP was higher 2-16 } \\
\text { minutes after exercise }\end{array}$ & $\begin{array}{l}\text { AP } \\
\text { Blood flow (strain gauge plethys- } \\
\text { mography) }\end{array}$ \\
\hline Hiatt et al. ${ }^{7}$ & Increase in blood flow & Increase in blood flow & $\begin{array}{l}\text { Blood flow (strain gauge plethys- } \\
\text { mography) }\end{array}$ \\
\hline Gardner et al. $^{8}$ & Increase blood flow & Increase in blood flow & $\begin{array}{l}\text { Blood flow (strain gauge plethys- } \\
\text { mography) }\end{array}$ \\
\hline Brendle et al. ${ }^{9}$ & $\begin{array}{l}\text { Increase in endothelial-dependent } \\
\text { dilation }\end{array}$ & $\begin{array}{l}60 \% \text { improvement in flow mediated } \\
\text { brachial artery diameter and resting } \\
\text { artery diameter }\end{array}$ & $\begin{array}{l}\text { Brachial artery diameter and } \\
\text { flow velocity measured by an } \\
\text { ultrasound system }\end{array}$ \\
\hline Lundgren et al. ${ }^{10}$ & $\begin{array}{l}\text { Oxidative enzyme activity in- } \\
\text { creases with physical activity }\end{array}$ & $\begin{array}{l}\text { Cytochrome-c oxidase (Cyt-ox) } \\
\text { activity increased with training }\end{array}$ & $\begin{array}{l}\text { Biopsies of calf muscle tissue, } \\
\text { Cyt-ox activity measured }\end{array}$ \\
\hline Holm et al. ${ }^{11}$ & $\begin{array}{l}\text { Restricted oxygen supply during } \\
\text { exercise increases oxidative } \\
\text { enzymes }\end{array}$ & $\begin{array}{l}\text { Activity mitochondrial succinic } \\
\text { oxidase increases with training. } \\
\text { Increased blood flow with training } \\
\text { but not correlated to MWD }\end{array}$ & $\begin{array}{l}\text { Biopsies of lateral vastus muscle } \\
\text { and medial head of gastrocne- } \\
\text { mius muscle } \\
\text { AP } \\
\text { ABI }\end{array}$ \\
\hline Sorlie and Myhre ${ }^{12}$ & $\begin{array}{l}\text { Increased oxygen extraction by } \\
\text { skeletal muscles }\end{array}$ & $\begin{array}{l}\text { Venous oxygen saturation was } \\
\text { lower at exhaustion after training } \\
\text { than before. Max lactate concen- } \\
\text { tration lower after physical training }\end{array}$ & $\begin{array}{l}\text { Catheter into distal femoral vein } \\
\text { and brachial artery }\end{array}$ \\
\hline Zetterquist ${ }^{13}$ & $\begin{array}{l}\text { Increased oxygen extraction by } \\
\text { the skeletal muscles attributed to a } \\
\text { regional redistribution of available } \\
\text { blood flow towards active muscles }\end{array}$ & $\begin{array}{l}\mathrm{O}_{2} \text { saturation of femoral venous } \\
\text { blood was significantly lower after } \\
\text { training at identical loads }\end{array}$ & $\begin{array}{l}\text { Catheter into femoral vein of } \\
\text { affected leg }\end{array}$ \\
\hline Hiatt et al. ${ }^{14}$ & $\begin{array}{l}\text { Improved skeletal oxidative me- } \\
\text { tabolism }\end{array}$ & $\begin{array}{l}\text { Decrease in resting plasma short- } \\
\text { chain acylcarnatine concentration }\end{array}$ & $\begin{array}{l}\text { Blood samples taken and carna- } \\
\text { tine measured by radioenzymatic } \\
\text { assay }\end{array}$ \\
\hline Parr et al. ${ }^{15}$ & Mechanism unclear & $\begin{array}{l}\text { Venous lactate concentrations low } \\
\text { at maximal exercise capacity and } \\
\text { not correlated to walking distances }\end{array}$ & $\begin{array}{l}\text { Blood samples from brachial } \\
\text { artery }\end{array}$ \\
\hline Ruell et al. ${ }^{16}$ & $\begin{array}{l}\text { Lower lactate concentrations after } \\
\text { physical training }\end{array}$ & $\begin{array}{l}\text { Venous lactate concentrations } \\
\text { lower at submax and at exhaustion }\end{array}$ & $\begin{array}{l}\text { Blood samples taken from bra- } \\
\text { chial artery } \\
\text { Walking distances }\end{array}$ \\
\hline Pedrinelli et al. ${ }^{17}$ & $\begin{array}{l}\text { Central drive increases following a } \\
\text { supervised walking programme }\end{array}$ & $\begin{array}{l}\text { Raised initial MDF but not to normal } \\
\text { values after the walking programme }\end{array}$ & $\begin{array}{l}\text { Muscle fibre conduction velocity } \\
\text { and median frequency of tibialis } \\
\text { anterior muscle }\end{array}$ \\
\hline Gardner et al. ${ }^{18}$ & $\begin{array}{l}\text { Improved pain tolerance through } \\
\text { exposure to pain }\end{array}$ & $\begin{array}{l}\text { Claudication pain end point used } \\
\text { during training was the most impor- } \\
\text { tant predictor of change in PFWD }\end{array}$ & Meta-analysis of controlled trials \\
\hline
\end{tabular}

studies proved that improvement in blood flow is due to an increased collateral circulation.

More recently a study in subjects with mild hypertension found that after 12 weeks of exercise training, forearm blood flow increased significantly in response to acetylcholine (an endothelium-dependent vasodilator) but not to isosorbide dinitrate (an endotheliumindependent vasodilator) in the exercise group but not in the control group. ${ }^{20}$ Studies using the elderly ${ }^{21,22}$ or patients with coronary artery disease ${ }^{23}$ and on animals with chronic coronary occlusion ${ }^{24}$ have revealed that exercise training improves endotheliumdependent vasorelaxation through an increase in the release of nitric oxide.

Endothelial cells release nitric oxide, a lipid-soluble gas, in response to the stimulus of increased blood flow through the vessel lumen (as would happen during exercise). ${ }^{25}$ Indeed, it is apparent that a depressed endothelial function is more likely to improve with exercise training than in patients with normal endothelial function (i.e. in the young and healthy). ${ }^{26}$ 
It has been shown in patients with PAD that endotheliumdependent dilation is impaired or depressed. This was shown by measuring maximum brachial artery diameter and flow after brachial artery occlusion (with a blood pressure cuff) in patients with PAD and controls. ${ }^{27}$ Only one study has shown that exercise rehabilitation improves endothelial-dependent dilation in older patients with PAD. ${ }^{9}$ This study found a $60 \%$ improvement in the flow-mediated brachial arterial diameter as well as in the resting arterial diameter. However, this study was not randomised or controlled.

It is perhaps the improved endothelial-dependent vasodilation that is responsible for improvements in walking tolerance and blood flow. It is possible that improved endothelial-dependent vasodilation in patients with PAD as a result of exercise training allows for a less pronounced and shorter duration post-exercise hyperaemic response and decrease in ankle pressure after a bout of exercise, which would explain the findings of the studies completed in the 1960s and 1980s.

Finally, it may not only be the endothelium that is responsible for vasodilation in patients with PAD. Further examination is also required of the ability of the smooth-muscle cells of the arteries to cause vasodilation in response to adenosine in patients with PAD. A study by Hambrecht et al. ${ }^{23}$ found that coronary blood flow reserve (the ratio of the mean peak flow velocity to the resting velocity after adenosine infusion) increased significantly after 4 weeks of training in patients with coronary artery disease. ${ }^{23}$ Future research should examine this response to exercise training in patients with PAD.

\section{Biochemical adaptations in skeletal muscle in} patients with PAD following exercise training

Because patients with PAD have reduced blood flow to the exercising limb(s), it has been suggested that anaerobic glycolysis resulting from ischaemia increases the lactate concentration in the skeletal muscles and blood, which leads to claudication pain. ${ }^{27,10}$

This was summarised in a review article by Tan et al. ${ }^{28}$ who stated, 'In patients with peripheral vascular disease, increasing the workload causes an inequality in the supply of and demand for oxygen. Aerobic generation of ATP becomes inadequate and anaerobic metabolism predominates. The result is an increase in lactic acid production, and a depletion of ATP and creatine phosphate, leading to pain.'

Support for this theory is found in studies that have shown that improvements in walking tolerance following exercise training in patients with PAD occur alongside increases in the number of oxidative enzymes found in the skeletal muscle, ${ }^{11,10}$ improvements in oxygen extraction by the skeletal muscles ${ }^{12,29}$ and a decrease in the concentration of acylcarnatines ${ }^{16}$ (produced during skeletal muscle ischaemia). The theory is that these adaptations delay the onset of anaerobic glycolyis, lactate accumulation and pain.

This theory of walking intolerance in patients with PAD stems from the popular cardiovascular/anaerobic theory of fatigue which suggests that fatigue develops when the exercising skeletal muscles fail to get enough oxygen to them and as a result have to rely on anaerobic glycolysis to produce enough ATP to continue exercising. ${ }^{30}$ A by-product of anaerobic glycolysis is lactate accumulation in the skeletal muscles and blood.

A recent study in this laboratory found that although venous lactate concentrations increased following a graded treadmill exercise test, the values were very low $(2.08 \pm 1.6$ to $3.28 \pm 1.39$ mmol. $I^{-1}$ ) and furthermore did not correlate to PFWD or MWD in patients with PAD. ${ }^{15}$ Others have found that venous and arterial lactate concentrations were higher in patients with PAD at maximal exercise capacity than in age-matched controls at maximal exercise capacity $^{29}$ and lower after surgical reconstruction or physical training in these patients. ${ }^{29,16}$ However, concentrations of blood lactate never reached higher than $4 \mathrm{mmol}^{-\mathrm{I}^{-1}}$ in these studies. Values in a normal population at maximal exercise capacity reach far greater values than this $\left(7.59 \mathrm{mmol} . \mathrm{I}^{-1}\right)$ and the subjects never experience claudication. ${ }^{31,32}$ In skeletal muscle, there was no significant difference in lactate concentration values between patients with PAD and controls at maximal exercise capacity. ${ }^{16}$

Therefore, the suggestion that accumulation of lactate in the skeletal muscles and blood leads to claudication pain, is unlikely. There has to be some other mechanism for the pain that patients with PAD experience.

\section{Muscle recruitment response to claudication and exercise training}

Recently it has been suggested that fatigue in the normal population develops when muscle recruitment is reduced by the motor cortex, causing exercise to terminate. This happens because inhibitory reflexes arise from the exercising muscles and feedback to the spinal cord and motor cortex, reducing skeletal muscle recruitment. This theory has been previously reviewed. ${ }^{33,34}$

The influence of the central nervous system on muscle recruitment is commonly measured using surface electromyography (EMG). EMG comprises of the sum of electrical contributions made by the active motor units which are detected by electrodes placed on the skin surface overlying the muscle. ${ }^{35} \mathrm{Few}$ studies have investigated muscle activity in patients with $P A D$ after interventions including exercise training response and percutaneous transluminal angioplasty (PTA). The only published studies investigating EMG in these patients have studied changes in median frequency (MDF, the frequency value which divides the power density spectrum of EMG signal into two equal halves), nerve conduction velocity of peroneal and tibial nerves $36,37,33,17$ and a recent case study investigating changes in EMG after angioplasty. ${ }^{38} \mathrm{~A}$ study conducted by Pedrinelli et al. ${ }^{17}$ examined muscle fibre conduction velocity (MFCV) and MDF of the tibialis anterior muscle during tetanic electrical stimulations in patients with PAD and controls. MFCV ranges did not differ significantly between patients and healthy controls. However, MDF of both the ischaemic and non-ischaemic legs were found to be significantly lower than the controls, as the healthy limb also showed a decrease in MDF. This finding suggests that chronic ischaemia was not the cause of lower MDF in patients with PAD. It is of interest to note that this study used a 3-week walking programme intervention, which resulted in improved exercise tolerance, raised initial MDF but not to normal values after the walking programme; and unchanged MFCV in patients with PAD. These findings suggest that central drive increases following a supervised walking programme and factors other than ischaemia and physical inactivity underlie the abnormal EMG signal in patients with PAD. A case study conducted by Albertus-Kajee et al. ${ }^{38}$ on a patient with PAD came to similar conclusions, where muscle activity in the diseased leg was found to increase after angioplasty. They explain this increase in EMG as a possible increase in central drive to the lower limbs after angioplasty, which resulted in an increase in functional capacity. Interestingly, the blood lactate concentrations were low ranging between 2.00 and $1.75 \mathrm{mmol}^{-1} \mathrm{I}^{-1}$ before angioplasty and $1.75-1.50 \mathrm{mmol}^{-1}$ after angioplasty.

The influence of muscle recruitment on the training response in these patients is therefore of special interest and needs to be further investigated. Although the use of EMG in the evaluation of this disease is still in early development, it provides a non-invasive assessment and understanding of the physiopathology of skeletal muscle involvement in patients with PAD. 


\section{Psychological adaptations to exercise training}

Some of the improvement in exercise tolerance noted with exercise training in patients with intermittent claudication may be attributed to psychological factors. This was made apparent in a review where a number of important predictors of the outcome of an exercise programme were identified. ${ }^{39}$ The best correlation with good outcome of the exercise programme was belief that the exercise would lead to an improvement in walking status. Moreover, patients can be influenced by the level of motivation they feel on the particular day of testing. This was made apparent in a study which noted: 'The psychology involved when walking with pain was highlighted by the two-thirds of patients who said they could walk no further but then immediately walked $15-45 \mathrm{~m}$ to the rest room, 40

Lastly it seems that as patients subject themselves to pain, their pain tolerance improves. Gardner et al. ${ }^{18}$ found in a meta-analysis that claudication pain end-point used during an exercise training programme was the most important independently related predictor of the positive change in PFWD distance and MWD in patients with intermittent claudication. ${ }^{18}$ The longer patients 'walked into' their pain during training, the more PFWD and MWD improved after training.

Therefore, factors including the belief that the exercise training will work, motivation to walk and improvements in pain tolerance can affect walking tolerance. If it is true that the motor cortex reduces muscle recruitment in response to pain then these psychological factors could perhaps act against central regulation, allowing for the patient to train longer and eliciting better functional results. This is an area of future research.

\section{Conclusion}

Early research attributed improvements in walking distances with exercise training to improvements in collateral circulation or peripheral adaptations in the exercising skeletal muscles. This review indicates that endothelium-dependent dilation improves with exercise training and should be researched further in controlled, randomised trials. Moreover, the possibility that the central governor causes exercise to terminate in patients with PAD should be investigated, especially in the light that factors including the belief that the exercise training will work, motivation to walk and improvements in pain tolerance affect walking distances in patients with PAD.

\section{REFERENCES}

1. Bernstein EF. Vascular Diagnosis. Missouri, Mosby-Year Book. 1993

2. Parr BM, Derman EW. The effects of exercise training in patients with peripheral vascular disease - a review. S Afr J Sports Med 2006;18(4):6772.

3. Skinner JS, Strandness DE. Exercise and intermittent claudication. Circulation 1967;6:23-29.

4. Alpert J, Larsen A, Lassen NA. Exercise and intermittent claudication: blood flow in the calf muscle during walking studied by the Xenon-133 clearance method. Circulation 1969;9:353-359.

5. Carter SA, Hamel ER, Paterson JM, Snow CJ, Mymin D. Walking ability and ankle systolic pressures: Observations in patients with intermittent claudication in a short-term walking exercise program. J Vas Surg 1989;10:642-649.

6. Jonason T, Ringqvist I. Effect of training on the post-exercise ankle blood pressure reaction in patients with intermittent claudication. Clin Phys 1986; 7:63-69.

7. Hiatt WR, Regensteiner JG, Wolfel EE, Carry MR, Brass EP. Effect of exercise training on skeletal muscle histology and metabolism in peripheral arterial disease. J Appl Physiol 1996;81:780-788.

8. Gardner AW, Katzel LI, Sorkin JD, et al. Exercise rehabilitation improves functional outcomes and peripheral circulation in patients with intermittent claudication: A randomised controlled trial. J Am Geriatr Soc 2001:49:755-762.

9. Brendle DC, Joseph LJO, Coretti MC, Gardner AW, Katzel LI. Effects of exercise rehabilitation on endothelial reactivity in older patients with peripheral arterial disease. Am J Cardiol 2001;87:324-329.
10. Lundgren F, Dahloff AG, Schersten T, Volkmann R. Intermittent claudication - surgical reconstruction or physical training. Ann Vasc Surg 1989;209:346-355.

11. Holm J, Dahloff AG, Bjorntorp P, Schersten T. Enzyme studies in muscles of patients with intermittent claudication. J Clin Lab Invest 1973;31:201-205.

12. Sorlie D, Myhre K. Effects of physical training in intermittent claudication. Scan J Clin Lab Invest 1978;38:217-222.

13. Zetterquist $S$. The effect of active training on the nutritive blood flow in exercising ischemic legs. Scand J Clin Lab Invest 1970;25(1):101-111.

14. Hiatt WR, Regensteiner JG, Hargarten ME, Wolfel EE, Brass EP. Benefit of exercise conditioning for patients with peripheral arterial disease. Circulation 1990;81:602-609.

15. Parr BM, Noakes TD, Derman EW. Factors predicting walking intolerance in patients with peripheral arterial disease and intermittent claudication. $S$ Afr Med J 2008;98:958-962.

16. Ruell PA, Imperial ES, Bonar FJ, Thursby PF, Gass GC. Intermittent claudication - The effect of physical training on walking tolerance and venous lactate concentration. Eur J App Physiol 1984;52:420-425

17. Pedrinelli R, Marino L, Dell'Omo G, Siciliano G, Rossi B. Altered surface myoelectric signals in peripheral vascular disease: correlations with muscle fiber composition. Muscle Nerve 1998;21:201-210.

18. Gardner AW, Poehlman ET. Exercise rehabilitation programs for the treatment of claudication pain. JAMA 1995;274:975-1000.

19. Basmajian JV. Therapeutic Exerise. 3rd ed. Baltimore: Williams and Wilkinson, 1978.

20. Higashi Y, Sasaki S, Kurisu S. Regular aerobic exercise augments endothelium dependant vascular relaxation in normotensive as well as hypertensive subjects. Circulation 1999;100:1194-1201.

21. Rinder MR, Spina RJ, Ehsani AA. Enhanced endothelium-dependant vasodilation in older endurance-trained men. J Appl Phys 2000;88:761-766.

22. Taddei S, Galetta F, Virdis A, et al. Physical activity prevents age-related impairment in nitric oxide availability in elderly athletes. Circulation 2000;101:2896-2901.

23. Hambrecht R, Wolf A, Gielen S. Effect of exercise on coronary endothelial function in patients with coronary artery disease. New Engl J Med 2000;342:454-460.

24. Griffin KL, Laughlin MH, Parker JL. Exercise training improves endothelium-mediated vasorelaxation after chronic coronary occlusion. J Appl Phys 1999:87:1948-1956.

25. Pohl U, Holtz J, Busse R, Bassenge E. Crucial role of endothelium in the vasodilator response to increased flow in vivo. Hypertension 1986;8:37-44.

26. Green DJ, Maiorana A, O Driscoll G, Taylor R. Effect of exercise training on endothelium-derived nitric oxide function in humans. J Physiol 2004;561(1):1-25

27. Yatoco AR, Corretti MC, Gardner AW, Womack CJ, Katzel LI. Endothelial reactivity and cardiac risk factors in older patients with peripheral arterial disease. Am J Cardiol 1999;83:754-758.

28. Tan $\mathrm{KH}$, De Cossart L, Edwards PR. Exercise training and peripheral vascular disease. Brit J Surg 2000;87:553-562.

29. Pernow B, Saltin B, Wahren J, Cronestrand R, Ekestrom S. Leg blood flow and muscle metabolism in occlusive arterial disease of the leg before and after reconstructive surgery. Clin Sci Mol Med 1975:49:265-275.

30. Noakes TD. Physiological models to understand exercise fatigue and the adaptations that predict or enhance athletic performance. Scand J Med Sci Sports 1999;9:1-23.

31. Benneke R, van Duvillard SP. Determination of maximal lactate steady state response in selected sports events. Med Sci Sports Exer 1996;28:241-246.

32. Nichols JF, Phares SL, Buono MS. Relationship between blood lactate response to exercise and endurance performance in competitive female masters cyclists. Int J Sports Med 1997;18:458-463.

33. Papapetropoulou V, Tsolakis J, Terzis S, Paschalis C, Papapetropoulos T. Neurophysiologic studies in peripheral arterial disease. J Clin Neurophysiol 1998;15:447-450.

34. Davis JM, Bailey SP. Possible mechanisms of central nervous system fatigue during exercise. Med Sci Sports Exerc 1997;29:45-57.

35. Farina D, Merletti R, Enoka RM. The extraction of neural strategies from the surface EMG. J Appl Physiol 2004;96:1486-1495.

36. Argyriou AA, Tsolakis I, Papadoulas S, Polychronopoulos P, Gourzis P, Chroni E. Dynamic F wave study in patients suffering from peripheral arterial occlusive disease. Acta Neurol Scand 2007:115:84-89.

37. McDermott MM, Guralnik JM, Albay M, Bandinelli S, Miniati B, Ferrucci L. Impairments of muscles and nerves associated with peripheral arterial disease and their relationship with lower extremity functioning: the $\mathrm{InCHI}$ ANTI Study. J Am Geriatr Soc 2004:52:405-410.

38. Albertus $Y$, Swart J, Lamberts R, Lambert MI, Noakes TD, Derman EW. Alteration in EMG during graded treadmill exercise test after 3 days recovery from angioplasty in a patient with peripheral vascular disease. Int Sports Med J 2011. In print

39. Rosfers A, Arnetz BB, Bygdeman S, Skoldo L, Lahnborg G, Eneroth P. Important predictors of the outcome of physical training in patients with intermittent claudication. Scan J Rehab Med 1990;22:135-137.

40. Watson CJE, Phillips D, Hands L, Collin J. Claudication distance is poorly estimated and inappropriately measured. Brit J Surg 1997;84:1107-1109. 